\title{
Ethics in Publication part 3: Conflicts of Interest
}

\author{
Authors \\ Michael Wallace, Deborah Bowman, Hilary Hamilton-Gibbs, Peter D. Siersema
}

Bibliography

DOI https://doi.org/10.1055/a-1044-2118

Published online: 16.12.2019 | Endoscopy 2020; 52: 94-95

(c) Georg Thieme Verlag KG Stuttgart · New York

ISSN 0013-726X
Corresponding author

Prof. Dr. Peter D. Siersema, Department of

Gastroenterology and Hepatology, Radboud University,

Medical Center, Geert Grooteplein Zuid 10, 6525 GA,

Nijmegen, The Netherlands

peter.siersema@radboudumc.nl

\section{PUBLICATION INFORMATION}

This article is being published jointly in Gastrointestinal Endoscopy and Endoscopy. Copyright (c) 2020 by the American Society for Gastrointestinal Endoscopy and Georg Thieme Verlag KG

\section{ABBREVIATIONS \\ COI conflict of interest \\ COPE Committee on Publications Ethics \\ ICMJE International Committee of Medical Journal Editors}

The goal of scientific publications is to advance and share knowledge through the scientific process. All scientific observations are, however, prone to bias. One form of bias that is particularly important is a financial conflict of interest (COI). The potential for financial gain can significantly influence how authors present, as well as how readers interpret, scientific data. Although it is not possible to eliminate these biases, it is critically important that such COls be disclosed so that readers can take them into account when interpreting scientific results. In this article, we review the principles of COI disclosure with regard to scientific publications, and we highlight how our journals manage such COls.

Several recent high-profile examples of nondisclosure of COls have raised the awareness of how this can inappropriately influence the scientific process [1,2]. Failure to disclose a relevant $\mathrm{COI}$ is a major ethical violation. Most scientific journals, including ours, follow the principles outlined by the International Committee of Medical Journal Editors (ICMJE) as well as the Committee on Publications Ethics (COPE). The ICMJE defines COls as "relationships with entities in the bio-medical arena that could be perceived to influence, or that give the appear- ance of potentially influencing, what you wrote in the submitted work" [3]. The scope of this relationship is quite broad. It includes relationships that are both directly influential, such as consulting income from a company that makes the specific product being studied, as well as more broadly influential, such as companies or other entities that make similar or competing products. For example, if a scientific article is about a particular endoscopic stent, any relationship with the manufacturer of that stent or the manufacturer of competing stents or related devices should be disclosed.

Other relevant conflicts of interest include patents or copyrights or other intellectual property related to the product or technique described in the publication, ownership of a company, or significant stock in a company. This may also extend to the spouse of the author. Of note, ownership of general stock funds, such as mutual funds or index funds, is generally not considered a COI because the purchase or sale of individual companies within those funds is outside of the control of the author.

The timeframe for inclusion varies somewhat from journal to journal. The ICMJE recommends a timeframe that includes any relationships or anticipated payments within the prior 36 months.

The author may not be the direct recipient of funds but should disclose consulting fees, research grants, or funds paid to the individual's institution on their behalf. Other nonfinancial support should also be reported, including the provision of drugs or devices, travel expenses, administrative support, or writing assistance.

In the United States, a central reporting system has been developed for this purpose. All medical companies that provide support to physicians are required to report on this Federal website [4]. Although there are known limitations and inaccuracies of these data, the site does provide a central and transparent source of information to crosscheck potential COIs. Our journals routinely crosscheck this website when articles are submitted from U.S.-based authors. This is particularly true for manuscripts that report on a specific company's product. In 
Europe, there is no equivalent centralized reporting system in place. Only in certain countries, such as France, Portugal, and Latvia, are medical device companies required by law to report support to physicians.

As editors we follow the guidelines set forth by COPE when managing suspected nondisclosure of a COI. Typically, we ask authors to clarify any discrepancies between what is reported by the authors on the COI form and what is reported on the Federal or national websites. In most cases, nondisclosure is inadvertent and can be corrected by simple completion of the COI forms. In more serious or repeated cases of nondisclosure, manuscripts may be rejected and the author sanctioned.

Ultimately it is the author's responsibility to disclose all potential COls. Several recent systems have made this process less burdensome. One such system is the Convey software, developed by the Association of American Medical Colleges [5], which allows authors to maintain an ongoing list of potential COls as well as relevant topics and dates. The Convey system works similarly to reference management software, which allows the author to maintain a database of potential COls and upload the information in a variety of formats, whether to journals, medical education programs, or their institutions.

In summary, complete disclosure of potential COIs is the authors' responsibility and should broadly include any entity that can influence or be perceived to influence the scientific work. Journal editors are responsible for ensuring that all COIs are published alongside the article. The trust that the general public as well as scientific colleagues have in the scientific process critically depends on such disclosure.

\section{Competing interests}

The authors declare that they have no conflict of interest.

\section{References}

[1] Ornstein C, Thomas K. Top cancer researcher fails to disclose corporate financial ties in major research journals. New York Times 2018 September 8

[2] Thomas K, Ornstein C. Doctors and disclosures. New York Times 2018 December 8

[3] ICMJE. Conflicts of interest. Available at: http://www.icmje.org/conflicts-of-interest/ Accessed August 21, 2019

[4] Search open payments. Available at: www.openpaymentsdata.gov Accessed August 21, 2019.

[5] Convey. Available at: https://www.aamc.org/services/498864/convey.html Accessed August 21, 2019 